\title{
La diferenciación espacial del envejecimiento demográfico en los núcleos urbanos del País Vasco
}

\author{
M. ${ }^{a}$ Pilar Gonzalez Yanci y M. ${ }^{a}$ José Aguilera Arilla
}

El contraste rural-urbano no hace sólo referencia al paisaje visual y a las actividades económicas, sino que también en estos medios se generan distintos comportamientos socioculturales, que, sin duda, inciden en la demografía.

En líneas generales ha habido un proceso de "envejecimiento" del campo y "rejuvenecimiento" de la ciudad, producido no sólo por los factores demográficos (natalidad, fecundidad, mortalidad...) sino, en muy buena medida, por los fenómenos migratorios (éxodo rural).

Pero la ciudad, al igual que el campo, no constituye un espacio homogéneo y, por tanto, la asociación ciudad-rejuvenecimiento puede inducir a error. Ya hemos dicho en otras ocasiones que las grandes ciudades europeas aparecen como núcleos jóvenes en el conjunto de sus países, porque están rodeadas de municipios, que constituyen sus áreas metropolitanas, y que tienen elevados porcentajes de jóvenes y muy pocos ancianos. En cambio los centros urbanos están sufriendo un proceso de envejecimiento muy acusado. Este proceso se mantendrá previsiblemente durante algunos años, tras los cuales, conforme la población anciana que hoy reside en el centro vaya desapareciendo, dará lugar a una despoblación por terciarización, salvo que nuevos factores, como los efectos derivados de la remodelación puesta en marcha en esta década, cambien el rumbo de los acontecimientos. En dicho proceso jugará un papel muy importante el tamaño de las ciudades, siendo más temprano en las grandes ciudades que en las pequeñas, donde la terciarización tendrá lugar con posterioridad.

Es una realidad que en las sociedades occidentales más desarrolladas se siente como un "problema" el proceso de envejecimiento de su 
población, por las repercusiones socioeconómicas que este hecho genera. Sin entrar en el debate de si es o no un problema real el del envejecimiento a nivel general del planeta, donde lo que hay es un claro predominio de la población muy joven, si que creemos que a escala menor dentro de un país o comunidad, el envejecimiento constituye un motivo de preocupación. En este contexto pensamos que tiene gran importancia conocer la localización espacial de las personas de más de 65 años, de modo que se puedan arbitrar las medidas oportunas para una mejor planificación social. Desde hace algún tiempo venimos estudiando dicha diferenciación espacial, pero centrándonos en el marco de la ciudad. El objetivo final es intentar hacer una tipologia de ciudades según la distribución interna de sus habitantes de más de 65 años y tratar de extraer normas generales de comportamiento en función de diversos factores como tamaño de la población, nivel de desarrollo, situación geográfica, etc.

El nivel de estudio deseado es la totalidad de las aglomeraciones urbanas de más de 50.000 habitantes y las capitales de provincia, aunque no alcancen esta cifra, la escala utilizada es el barrio, o en su defecto, la sección censal o estadística, ya que otras unidades mayores, como el distrito, enmascaran la realidad y no permiten conocer la distribución real. En esto radica una de las mayores dificultades del trabajo, dado que no se publican datos estadísticos al nivel citado, ni todos los ayuntamientos brindan las mismas facilidades a la hora de dar la información que necesariamente ha de recabarse de ellos.

En anteriores ocasiones hemos publicado resultados parciales de Madrid y su Comunidad y de algunas de las ciudades costeras del levante español (Barcelona, Valencia, Castellón de la Plana y Alicante), ciudades todas que corresponden a provincias que en 1981 presentaban los más bajos índices de envejecimiento del pais (vid bibliografía). En este artículo daremos cuenta de la situación de las ciudades de más de 50.000 habitantes de una Comunidad Autónoma, el País Vasco, constituida por tres provincias de las que hemos conseguido un magnífico nivel de información que, desgraciadamente, no creemos que sea posible obtener para todo el país.

La Comunidad Autónoma vasca consta de tres provincias en las que además de sus capitales hay seis ciudades de más de 50.000 habitantes, cinco de ellas en Vizcaya, todas próximas a la capital, Baracaldo, Basauri, Santurce, Portugalete y Guetxo, y una en Guipúzcoa algo más alejada, Irún. 
En el conjunto nacional el País Vasco constituye una de las regiones de menor grado de envejecimiento, coincidiendo con el resto de la periferia. Recordemos que con un valor global del $11,3 \%$ de ancianos en 1981, en el país, hay un contraste entre la periferia rejuvenecida y el interior envejecido, con las excepciones de Madrid, que estando en el interior es más joven que el resto y Galicia, que siendo costera está más envejecida.

En los resultados obtenidos en los estudios parciales antes citados, pudimos apreciar que en las ciudades hay una clara diferenciación espacial del grado de envejecimiento por barrios o secciones. Los centros urbanos aparecen más "viejos" que su periferia, además al haber estudiado ciudades de distinto tamaño, pudimos constatar que se apreciaba una mayor concentración de ancianos en el centro, cuanto mayor era el tamaño de la ciudad. Ahora estamos en presencia de una comunidad en la que hay tres capitales de tamaño medio a bajo, una cuarta ciudad cercana a los 100.000 habitantes, otra de más de 75.000 y cuatro de valores en torno a $\mathbf{5 0 . 0 0 0}$ habitantes. Analizaremos en todas ellas la distribución de sus ancianos con la misma metodología utilizada en las antes expuestas, para poder comparar los resultados obtenidos.

En el Cuadro I podemos ver los porcentajes globales de envejecimiento para cada una de estas ciudades y para el total provincial, observándose que se trata de valores bajos en todos los casos, salvo en San Sebastián que está por encima de la media nacional. Es de destacar que

\section{CUADRO I}

\begin{tabular}{|c|c|c|}
\hline & Población & $\%$ Ancianos \\
\hline Vitoria $\ldots$ & 199.445 & 8,9 \\
\hline Bilbao & 381.506 & 10,81 \\
\hline San Sebastián & 175.138 & 12,21 \\
\hline Baracaldo .... & 114.094 & 8,59 \\
\hline Guetxo $\ldots \ldots \ldots \ldots \ldots$ & 77.856 & 8,42 \\
\hline Portugalete & 57.794 & 7,29 \\
\hline Irún $\ldots . . . .$. & 54.043 & 9,14 \\
\hline Santurce .... & 52.502 & 7,08 \\
\hline Basauri $\ldots \ldots \ldots \ldots \ldots \ldots \ldots \ldots$ & 51.931 & 6,5 \\
\hline Provincia de Álava ... & 267.724 & 9,7 \\
\hline Provincia de Vizcaya & 1.176 .565 & 10,2 \\
\hline Provincia de Guipúzcoa ......... & 687.738 & 10,6 \\
\hline
\end{tabular}


los porcentajes de ancianos de las ciudades de más de 50.000 habitantes de Vizcaya, todas cercanas al municipio de la capital, Bilbao, son especialmente bajos, recordando la situación de Madrid y su área metropolitana.

Utilizando en todos los casos como unidades espaciales de estudio las secciones censales (que no siempre corresponden fielmente a una distribución concéntrica), hemos procedido a cartografiar los valores de porcentajes de ancianos e índice de envejecimiento, para poder establecer después, conforme a la metodología aplicada en los trabajos anteriores, la correlación existente entre grado de envejecimiento y distancia al centro urbano. Hemos considerado siempre como centro aquel que era así sentido por los propios habitantes, dándose una correspondencia general entre éste y el que podemos considerar histórico. La distancia se ha medido a escala del mapa de forma lineal, sin tener en cuenta hechos como el relieve y la accesibilidad, dada la dificultad que ofrece su valoración, aunque son aspectos muy relevantes, que de contemplarse mejorarian, sin duda, la calidad de los resultados.

\section{Bilbao}

La mayor ciudad es Bilbao, con una población total de 381.506 habitantes y un porcentaje de ancianos de 10,81 superior en $0,61 \%$ a su provincia, repartidos en 290 secciones, correspondientes a 14 distritos. En el Mapa 1, donde se han cartografiado los porcentajes de ancianos, se observa que el centro está muy envejecido, con valores por encima del $23 \%$.

Los datos del Cuadro II corresponden a las secciones con valores más elevados de envejecimiento situadas en su mayor parte en el centro (distritos de Abando, Indautxu y Begoña) junto a otras secciones dispersas en otros distritos (Deusto, San Ignacio y Basurto). En casi todos los casos se observa que la población de la sección correspondiente es menor que las de su entorno, lo que parece indicar que hay un proceso de terciarización, con la consiguiente despoblación.

En torno a este centro envejecido, que corresponde a los barrios más antiguos de la ciudad y a las zonas más próximas del ensanche del siglo XIX, hay un gran número de secciones con valores entre el 19 y el $23 \%$ que corresponden al resto del ensanche, edificado en fechas pos- 


\begin{tabular}{|c|c|c|}
\hline \multicolumn{3}{|c|}{ CUADRO II } \\
\hline Distrito & Sección & $\%$ Ancianos \\
\hline IX (Abando) & 13 & 24,32 \\
\hline$»$ & 14 & 25,00 \\
\hline$》$ & 16 & 25,47 \\
\hline$\gg$ & 17 & 23,20 \\
\hline 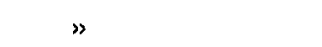 & 18 & 23,67 \\
\hline$"$ & 20 & 23,13 \\
\hline ” & 21 & 23,40 \\
\hline$»$ & 22 & 24,27 \\
\hline X (Indautxu) & 7 & 28,23 \\
\hline 》 & 10 & 25,98 \\
\hline VI (Begoña casco) & 3 & 24,53 \\
\hline 》 & 5 & 27,90 \\
\hline$»$ & 6 & 24,44 \\
\hline XI (Amezola Irala) & 17 & 24,34 \\
\hline XIII (Basurto) & 2 & 40,31 \\
\hline
\end{tabular}

teriores (Mapa 1). Destaca la presencia de unos núcleos muy envejecidos fuera del citado centro. Corresponden a los distritos de Deusto y San Ignacio, que se anexionaron a comienzos de siglo y que son zonas de antiguo poblamiento, favorecido por la construcción del ferrocarril BilbaoLas Arenas y la Universidad. Alli se levantaron también, en los años veinte, barriadas de viviendas obreras, hoy envejecidas y, por último alli existe una residencia de ancianos.

Rodeando las áreas de mayor porcentaje de ancianos se van sucediendo un mosaico de secciones, que dado su pequeño tamaño no resultan homogéneas, pero en las que se va marcando un gradiente descendente de envejecimiento.

Estructuralmente (Mapa 2) se observa que sólo las secciones más periféricas están por debajo del índice 0,5 de $\mathrm{V} / \mathrm{J}$ (límite de envejecimiento según Veyret-Verner), siendo todo el interior envejecido, es decir con una débil proporción de jóvenes, que indica que el proceso evolucionará a un envejecimiento mayor en el futuro.

Al establecer matemáticamente la relación entre porcentaje de ancianos y distancia al centro, obtenemos un coeficiente de correlación lineal muy bajo, $-0,35$. El ajuste a una curva de ecuación $y=a x^{* *} b \rightarrow$ da un coeficiente de correlación más alto, $-0,45$. No obstante son valores ba- 
jos, comparados con los obtenidos en otras ciudades, pese a que la cartografia es similar. El motivo está en la distorsión que producen las anomalías que hemos comentado: los barrios de antiguo poblamiento de Deusto y San Ignacio y la sección XIII.2. que tiene un porcentaje de ancianos de 40,3, debido a la existencia de la Casa de Misericordia. Al eliminar dichas anomalias obtenemos un coeficiente de correlación de $-0,52$ valor mucho más cercano a los obtenidos en otras ciudades (Valencia, Alicante) (vid gráficos).

\section{San Sebastián}

Con una población de 175.138 habitantes cuenta con ocho distritos que totalizan 119 secciones. Cartografiados los porcentajes de ancianos por secciones, se observa (Mapa 3) que hay dos distritos (el I y el II), que coinciden con lo que se considera el centro real e histórico de la ciudad, que superan en su totalidad el valor de $23 \%$ de ancianos, pero donde hay que resaltar que aparecen valores muy elevados (vid Cuadro III).

En torno a este centro se disponen, como una aureola, secciones más jóvenes entre las que algunas presentan valores algo superiores a las de su entorno, coincidiendo con núcleos más antiguos de poblamiento a lo largo de los principales accesos.

Estructuralmente tan sólo las secciones más exteriores están por debajo del índice 0,5 de $\mathrm{V} / \mathrm{J}$, mientras que el casco urbano supera en gran medida el valor del índice 1 , lo que indica que el grado de envejecimiento va a aumentar a futuro.

CUADRO III

\begin{tabular}{cccc}
\hline & Distrito & Sección & \% Ancianos \\
\hline II & 5 & 44,09 \\
II & 1 & 33,96 \\
III & 3 & 27,98 \\
\end{tabular}


El coeficiente de correlación entre la distancia al centro y el porcentaje de ancianos arroja un valor alto de $-0,72$, similar a los hallados en Madrid y Barcelona. En este caso no hemos realizado ninguna corrección, por no detectarse anomalías destacables. Resulta algo sorprendente esta elevada correlación, que parece excepcional en relación a su tamaño (según los resultados obtenidos en las ciudades estudiadas, vid Cuadro IV). Las conclusiones finales, tras el estudio de todo el país harán preciso un análisis de las razones que lo puedan explicar.

\section{Vitoria}

Vitoria tiene una población de 199.445 habitantes distribuidos en siete distritos, con un total de 137 secciones estadísticas. En el Mapa 5 se han cartografiado los porcentajes de ancianos, resultando que el centro urbano representado en los distritos I y II tiene algunas secciones con alto grado de envejecimiento, que en el caso extremo (sección 1.9 del casco viejo) tiene $45,5 \%$. El centro real actual está también muy envejecido, con valores de $32,5 \%$ (II.1) y $23,3 \%$ (l.1). El resto del centro también está envejecido, sin llegar a valores tan altos como los citados, pero siempre por encima de la cifra del $15 \%$ de personas de más de 65 años (Mapa 5).

Hacia la periferia las secciones van mostrando un menor grado de envejecimiento, siendo de destacar que éste es mayor por el Sur que por el Norte. Aparecen algunas anomalías dignas de mención. Por un lado hay dos secciones muy exteriores con alto grado de envejecimiento (la III.36 y la VI.10) porque albergan sendas residencias de ancianos. De igual modo el gran porcentaje de ancianos comentado en la sección 1.9 está incrementado por contar con la tercera residencia de la ciudad. Por otro lado algunas secciones del distrito VII, que abarca toda la periferia de Vitoria, presentan unos valores más altos de lo que les correspondería, debido a que son pequeños núcleos rurales de antiguo poblamiento, hoy anexionados a la ciudad (Elorriaga, Gamarra Mayor, Betoño, Zuazo y Armentia).

Estructuralmente (Mapa 6) queda más patente el contraste entre el centro envejecido y la periferia más joven. En este caso casi toda la periferia (salvo las anomalías comentadas) tiene un índice $\mathrm{V} / \mathrm{J}$ inferior a 0,5 . 
En Vitoria al establecer la relación entre la distancia al centro y el porcentaje de ancianos se obtiene un coeficiente de correlación lineal de $-0,47$, valor de poca significación. Al corregirlo eliminando las dos anomalias periféricas (residencias de ancianos) y dividiendo el valor hallado en la sección 1.9 por dos, de modo que le damos el valor medio de la zona, ya que el real de $45,5 \%$ tiene un efecto multiplicador y distorsionante, se eleva a $-0,53$, de mayor significación. Si se ajusta a una curva, como en el caso de Bilbao se obtiene un coeficiente de correlación de 0,64 y corregido de $-0,67$.

\section{Ciudades no capitales de provincia de más de $\mathbf{5 0 . 0 0 0}$ habitantes.}

El resto de las ciudades a estudiar son, como indicábamos, las que dentro de la Comunidad sobrepasan el límite considerado de más de 50.000 habitantes. Hay diferencias entre ellas, que se reflejan en su grado de envejecimiento.

Por un lado tenemos Irún, que es la única ciudad de estas características de la provincia de Guipúzcoa. Es un núcleo urbano con entidad propia desde antiguo, que ha experimentado un crecimiento en las últimas décadas, contando con 54.043 habitantes. Tiene el más elevado porcentaje de ancianos de las consideradas $(9,14 \%)$. El resto son ciudades de Vizcaya, que como hemos dicho se encuentran cercanas a la capital, incluso formando un continuo urbano (margen izquierda de la ría de Bilbao: Santurce, Baracaldo, Portugalete y Basauri y en la margen derecha, Guetxo). Sus características difieren entre sí. Baracaldo y Portugalete son municipios con entidad desde el siglo XIX como pequeñas ciudades, Santurce y Basauri eran pueblos de menor tamaño. Todos ellos han crecido en las últimas décadas por inmigración, al constituir una poderosa región industrial. Guetxo, en cambio, es una antigua zona de segunda residencia convertida hoy en área de expansión residencial de Bilbao en la que es dificil considerar el centro urbano, ya que resulta de la anexión de Las Arenas, Algorta y Guetxo propiamente.

Todas las diferencias expuestas se reflejan en los valores de envejecimiento, en la distribución espacial del mismo y en el coeficiente de correlación de los porcentajes de ancianos y la distancia al centro.

En todas estas ciudades hay un bajo nivel de envejecimiento (vid Cuadro I). No aparece ninguna sección que supere el valor del $23 \%$ de ancianos que encontrábamos en las capitales de provincia. Sólo en las 
que tenían entidad propia desde antiguo aparece un centro más envejecido, con valores entre el 19 y el $23 \%$.

La observación de los mapas (números 7 al 18) muestra la distribución espacial por secciones de cada una de las ciudades, así como su distribución estructural, en la que se muestra su escaso envejecimiento, con un claro predominio de secciones con índice inferior al 0,5.

La correlación entre distancia al centro y porcentaje de ancianos resulta baja. Tan sólo Irún con un coeficiente de correlación de -0,56 es comparable a las capitales de provincia. Le siguen Portugalete y Baracaldo, con $-0,35$ y $-0,33$. Basauri no presenta ninguna correlación $(-0,16)$ ya que es una zona de reciente expansión. Por último hay dos claras anomalías que presentan coeficientes de correlación muy bajos y además de signo contrario, es decir, más jóvenes en el centro que en la periferia. Se puede explicar fácilmente, Guetxo, como se ve en el mapa, tiene dos centros que corresponden a Las Arenas y Guetxo propiamente dicho, en los que hay cierta concentración de ancianos. Santurce no tiene centro envejecido y el valor positivo se debe a que en su periferia hay una residencia de ancianos, que da a la sección donde se halla un alto porcentaje (vid. gráficos).

\section{Conclusión}

En las ciudades vascas aparece, tras el estudio realizado, que las capitales de provincia tienen una distribución espacial de los ancianos similar a la que se da en otras capitales españolas. En todas ellas hay un centro envejecido y un gradiente descendente hacia la periferia, dándose coeficientes de correlación lineal significativos (Cuadro IV). En cambio en las ciudades de más de 50.000 habitantes estos coeficientes son bajos y tanto más cuanto más reciente es el crecimiento, en el que juega un papel decisivo la inmigración, que tiene a su vez mucho que ver con la actividad industrial. 
CUADRO IV

\begin{tabular}{|c|c|c|}
\hline Ciudad & $\begin{array}{c}\text { Coeficiente de } \\
\text { correlación } \\
\% \text { ancianos/distancia } \\
\text { al centro }\end{array}$ & Población 1986 \\
\hline Madrid & $-0,75$ & 3.057 .952 \\
\hline Barcelona & $-0,81$ & 1.701 .812 \\
\hline Valencia . & $-0,67$ & 729.419 \\
\hline Alicante $\ldots$ & $-0,67$ & 258.808 \\
\hline Castellón de la Plana & $-0,45$ & 133.246 \\
\hline Bilbao & $-0,52$ & 381.506 \\
\hline San Sebastián & $-0,72$ & 175.138 \\
\hline Vitoria $\ldots . . .$. & $-0,53$ & 199.445 \\
\hline Baracaldo & $-0,33$ & 114.094 \\
\hline Guetxo $\ldots .$. & $+0,22$ & 77.856 \\
\hline Portugalete ... & $-0,35$ & 57.794 \\
\hline Irún $\ldots \ldots \ldots$ & $-0,56$ & 54.043 \\
\hline Santurce & $+0,01$ & 52.502 \\
\hline Basauri .... & -0.16 & 51.931 \\
\hline
\end{tabular}


La diferenciación espacial del envejecimiento demográfico...

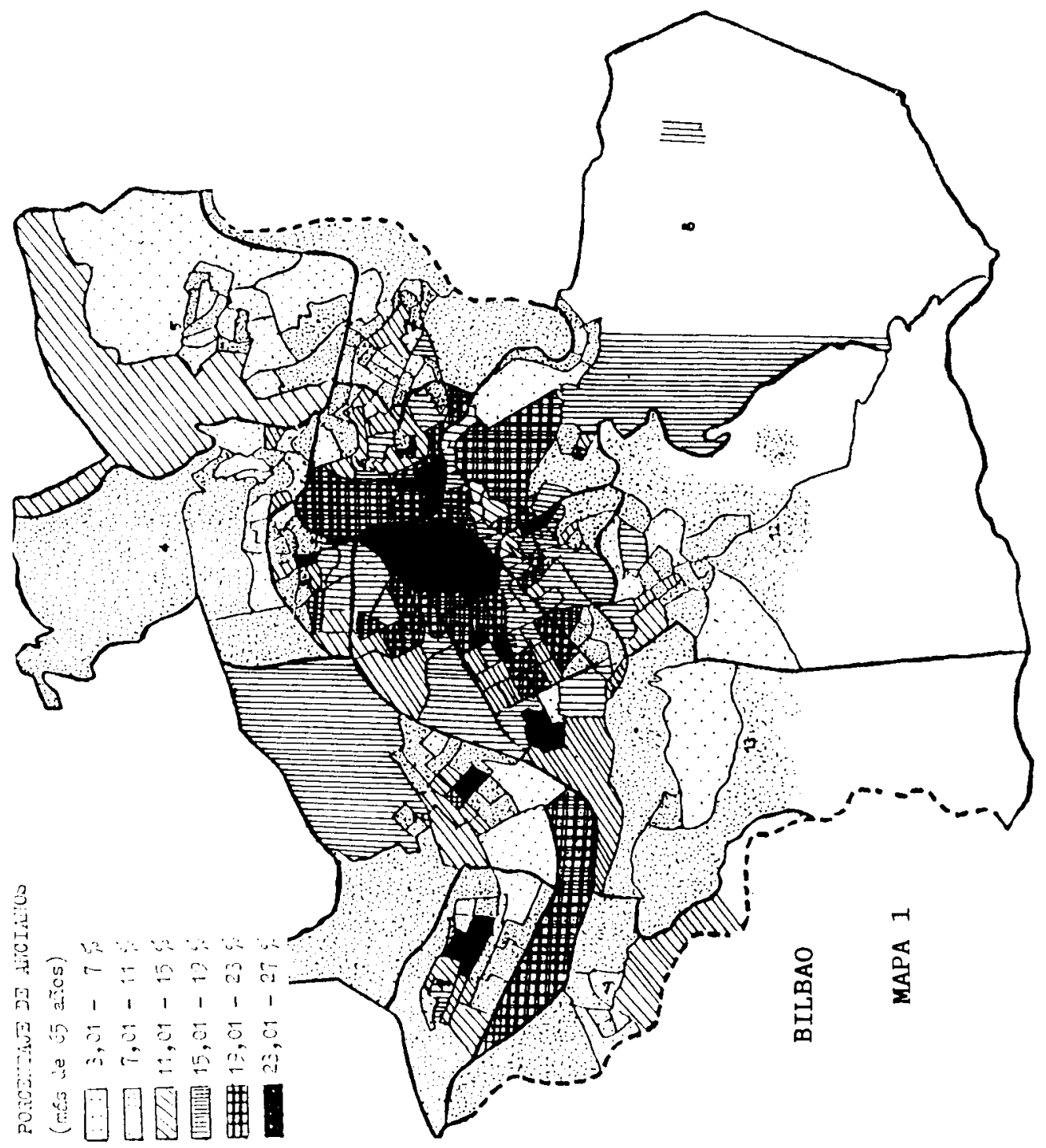




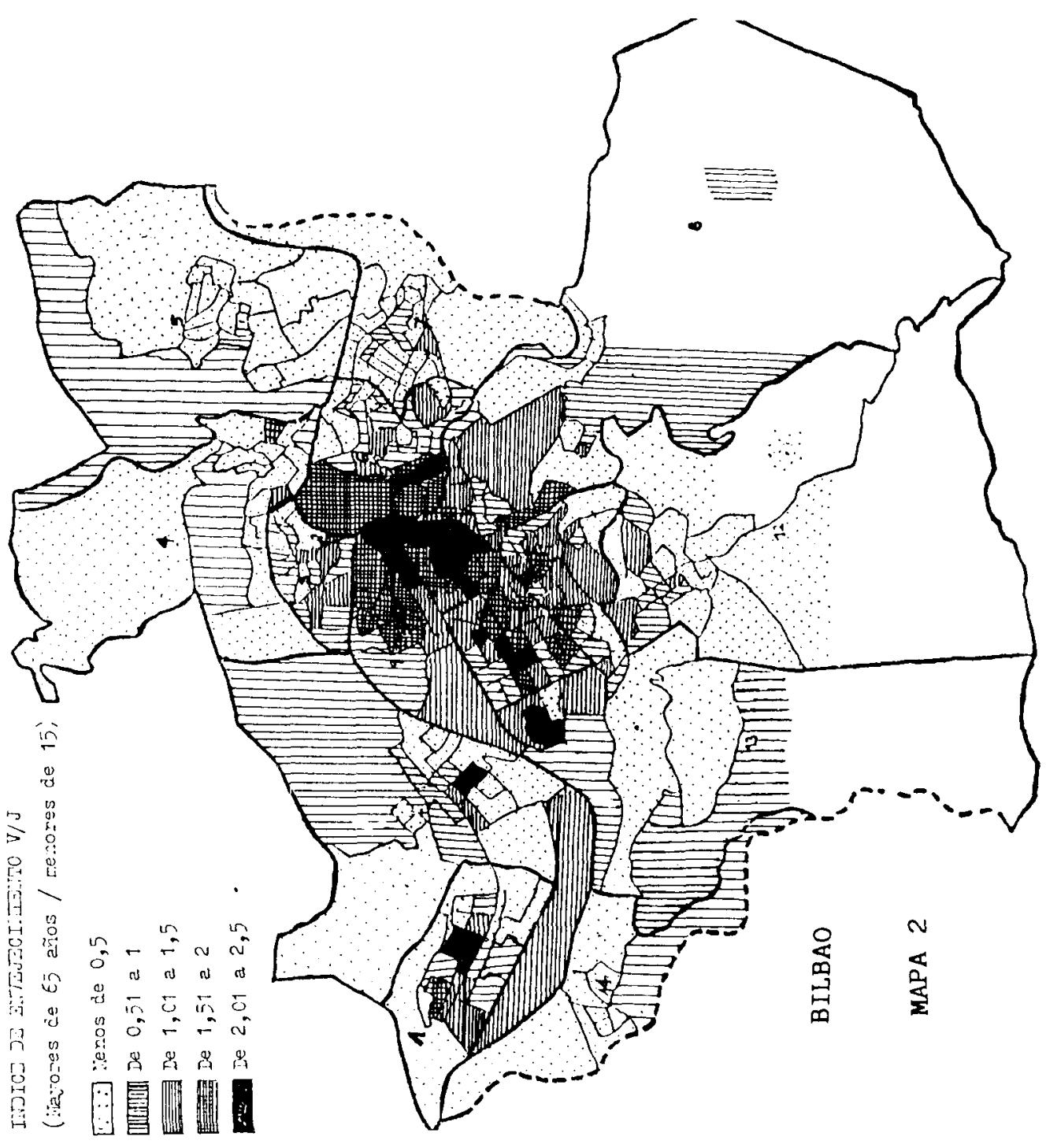




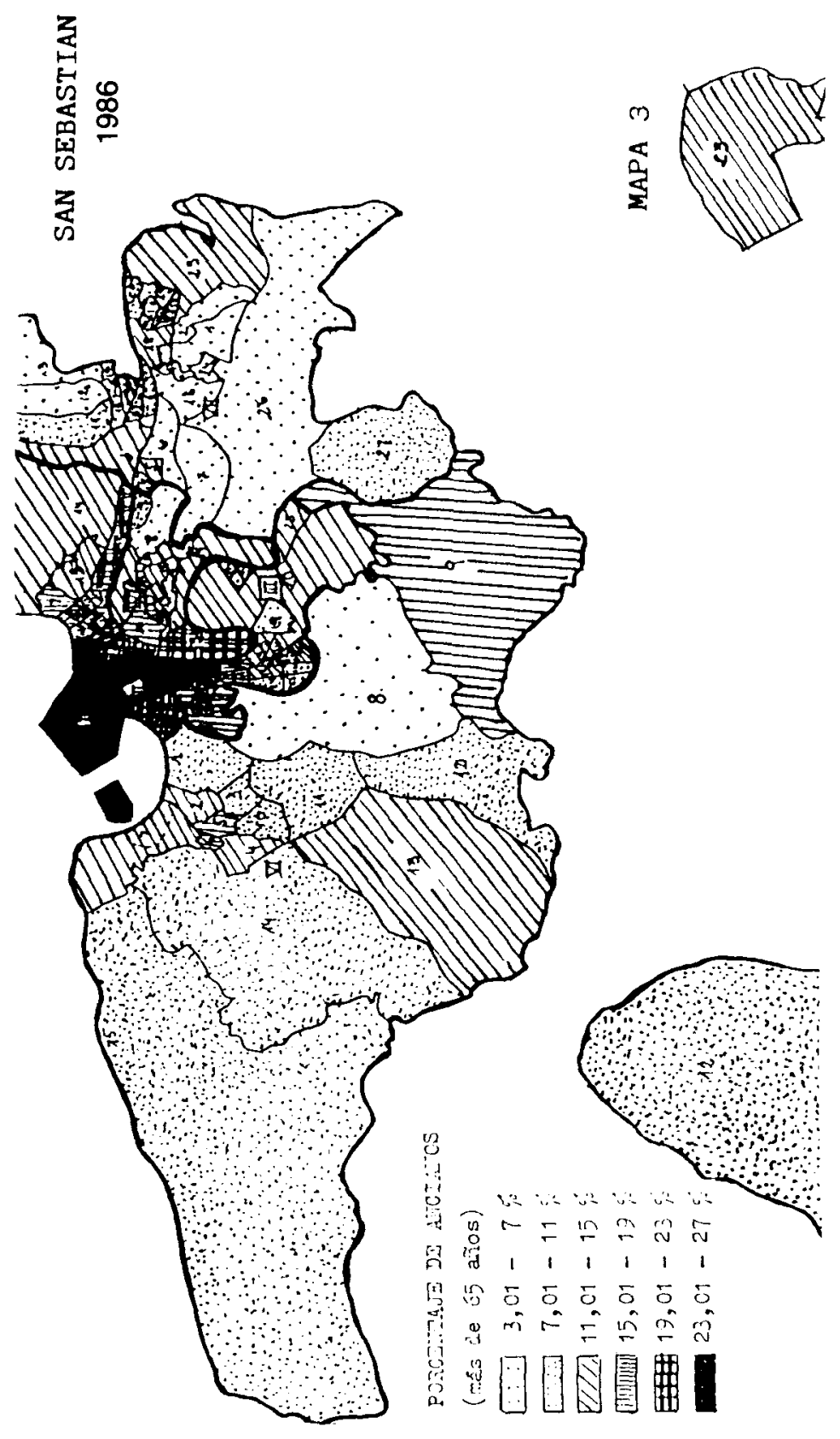




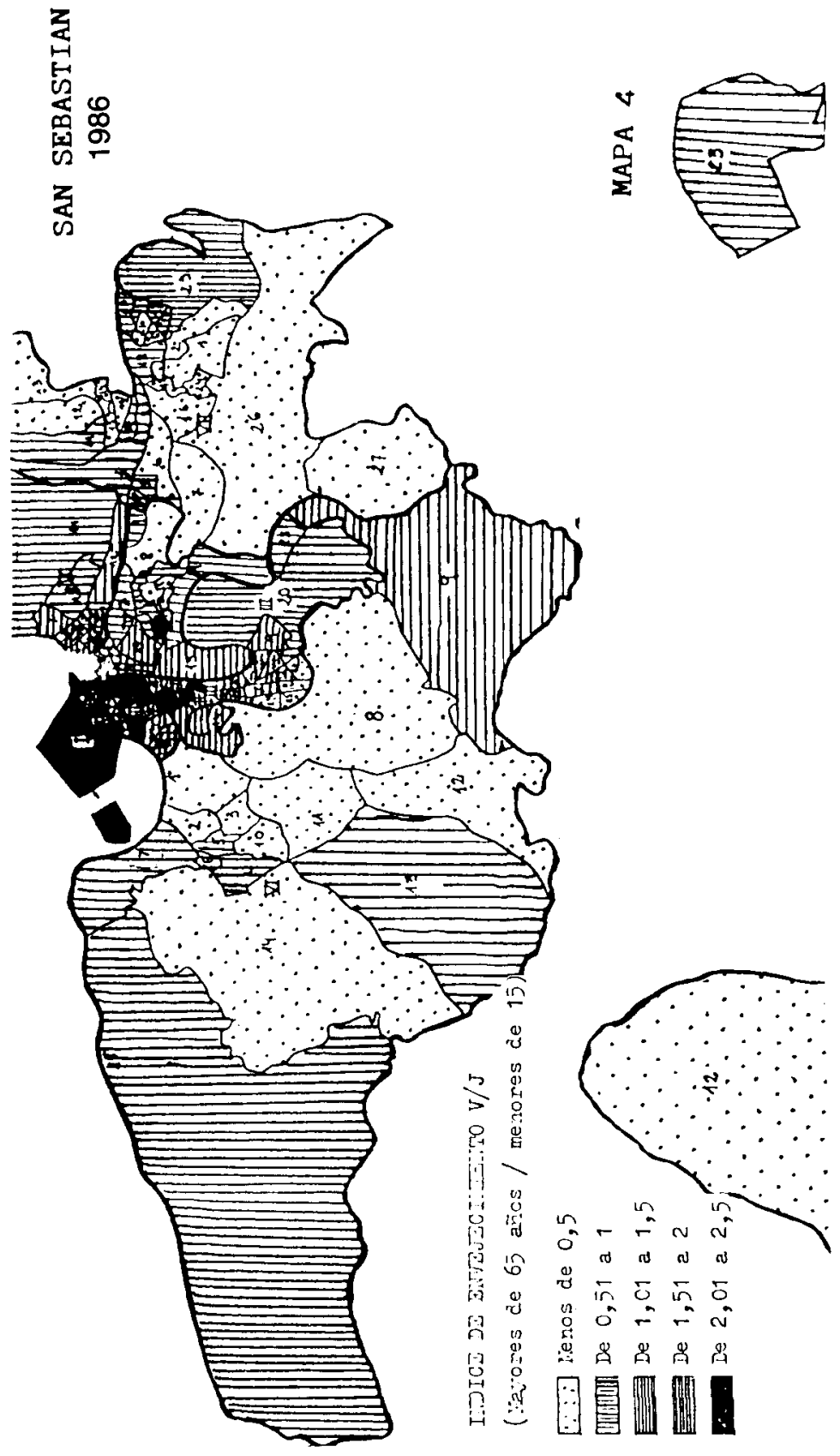


La diferenciación espacial del envejecimiento demográfico...

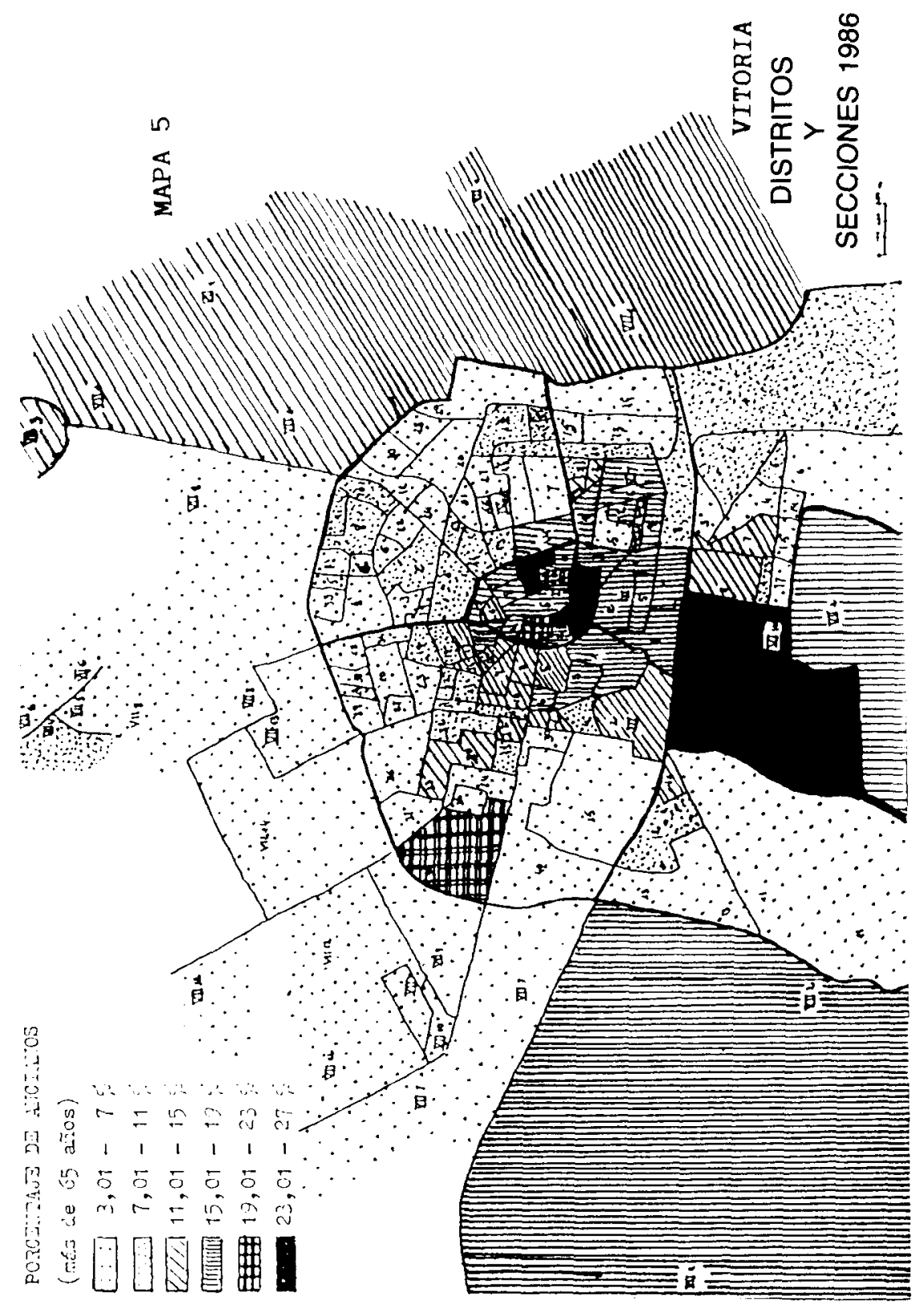




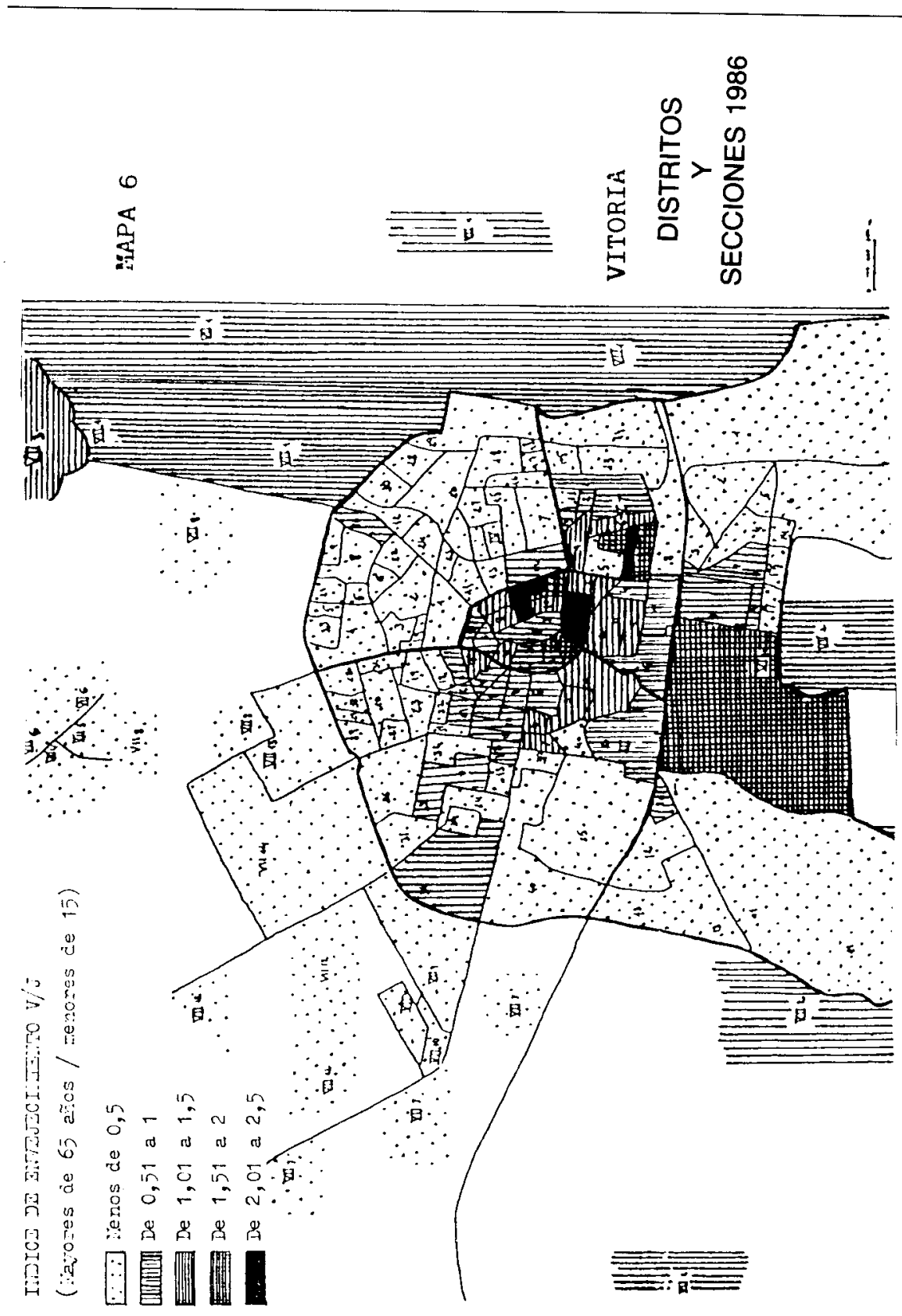


La diferenciación espacial del envejecimiento demográfico...
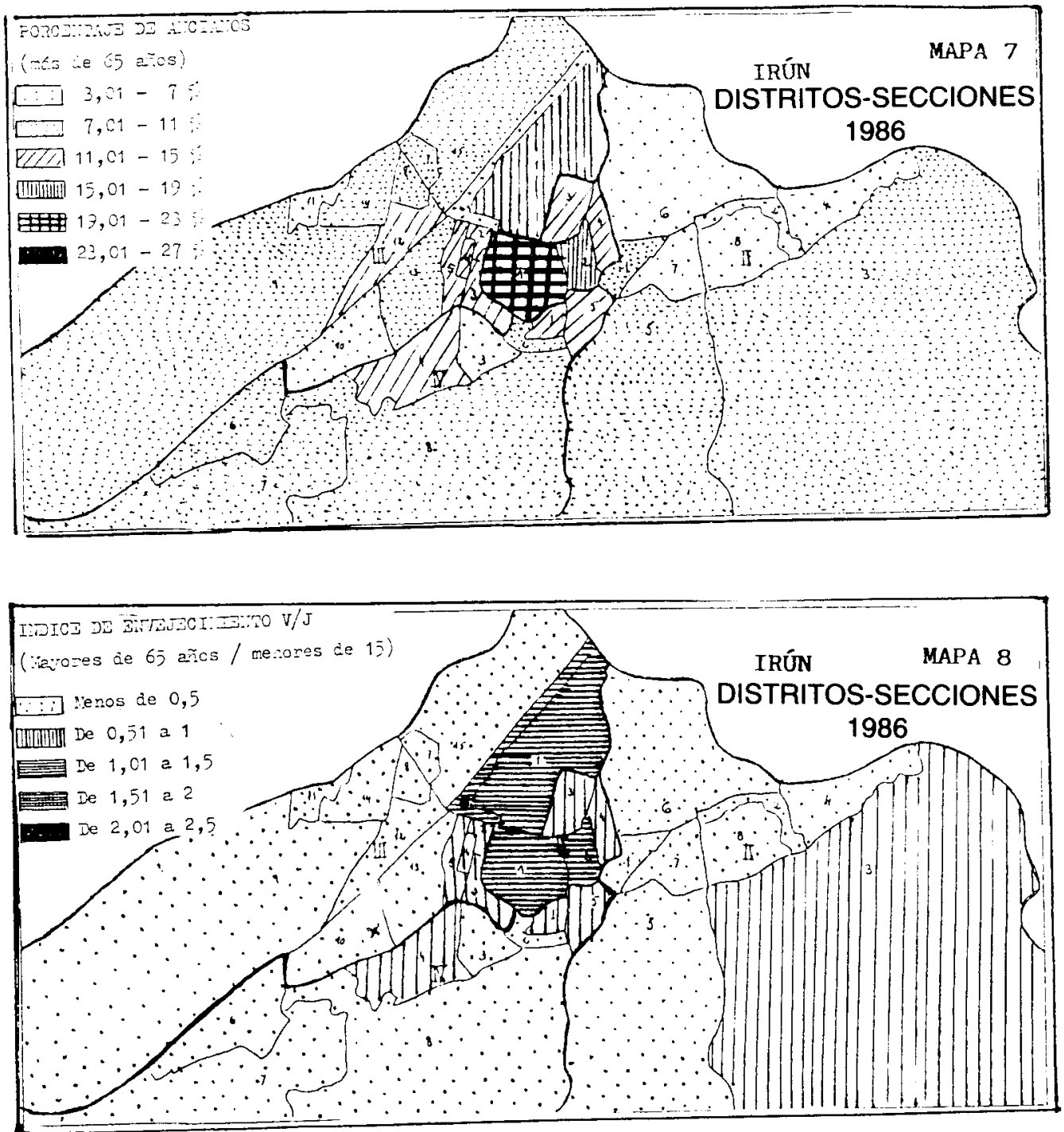


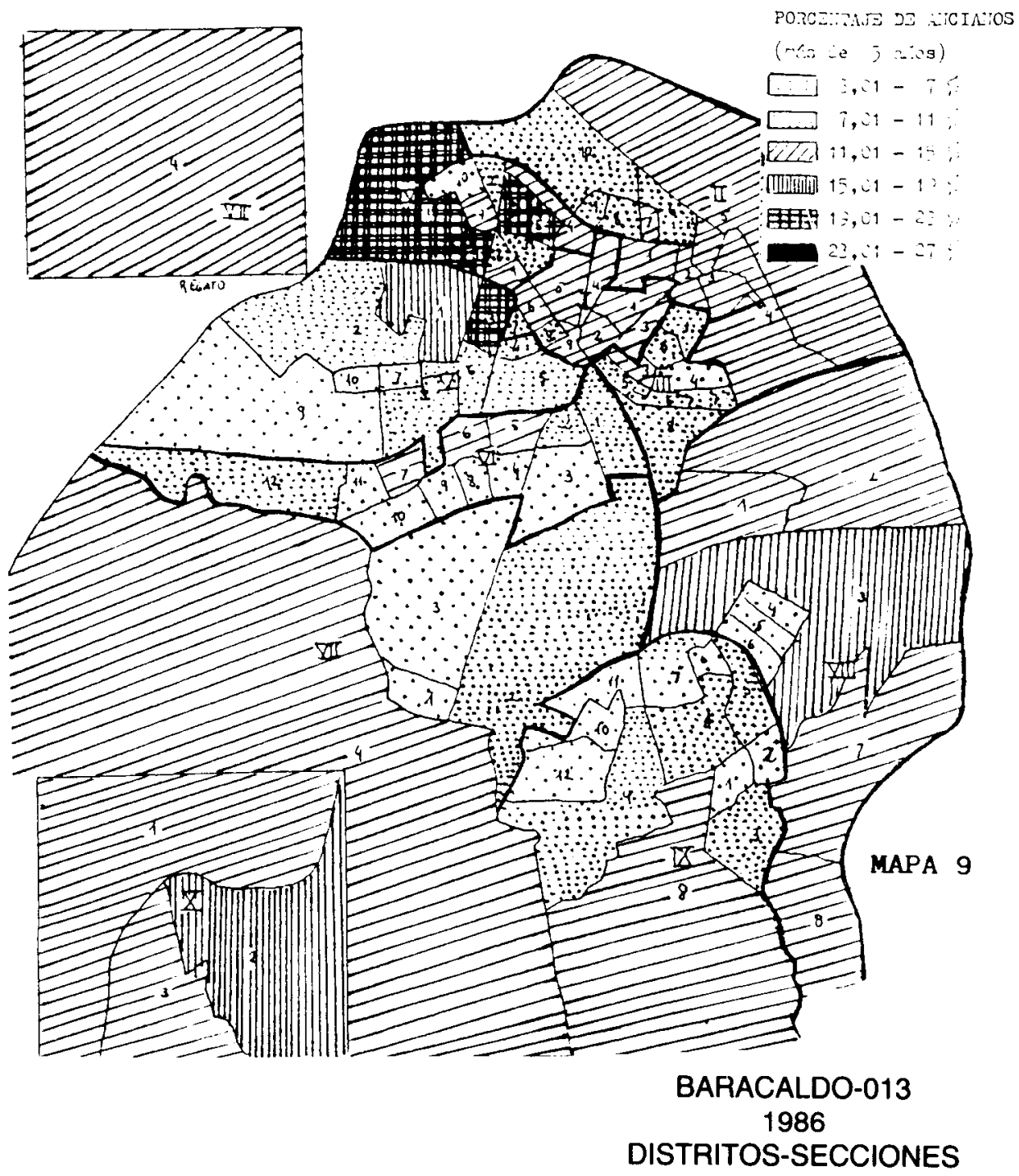




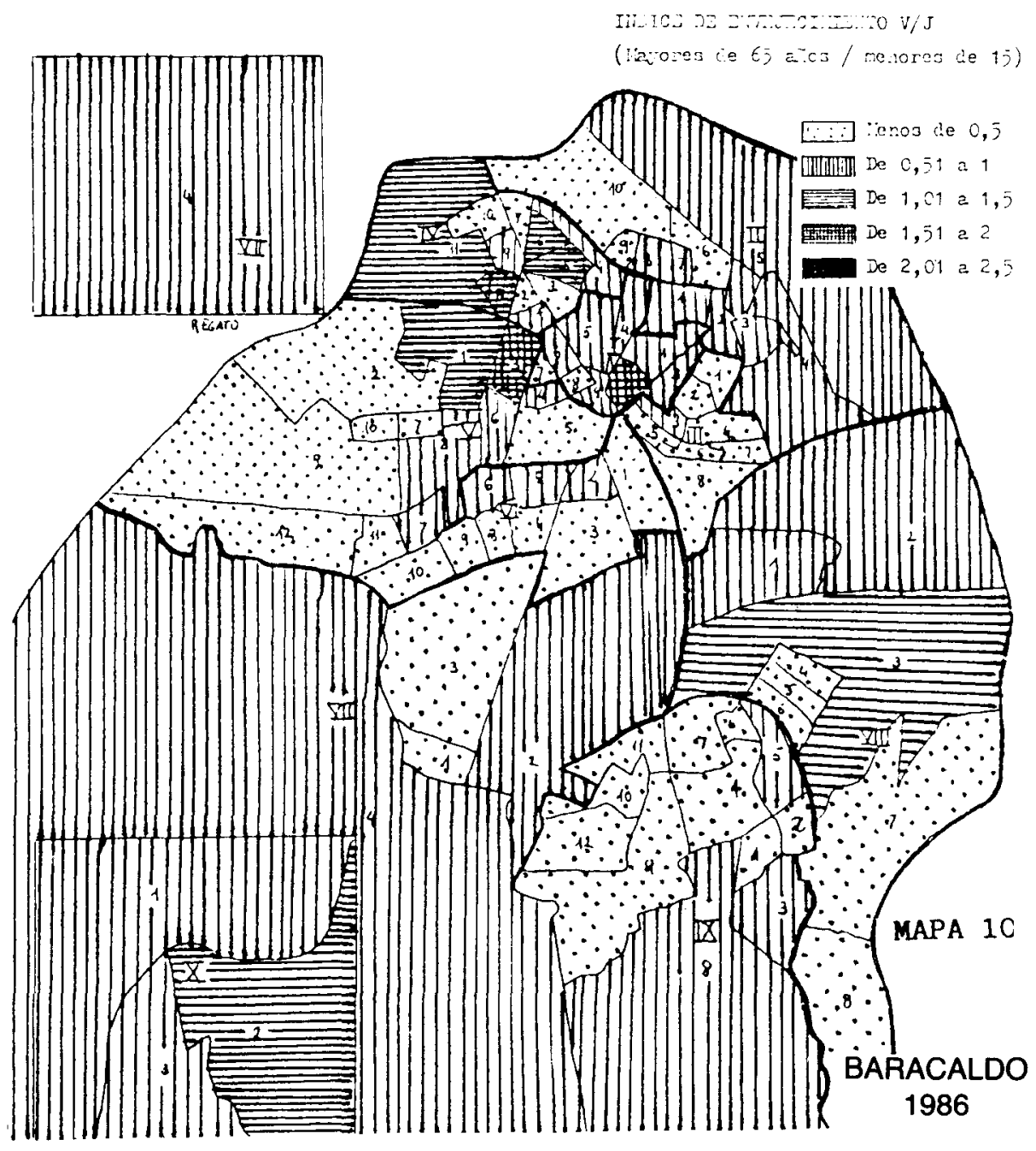




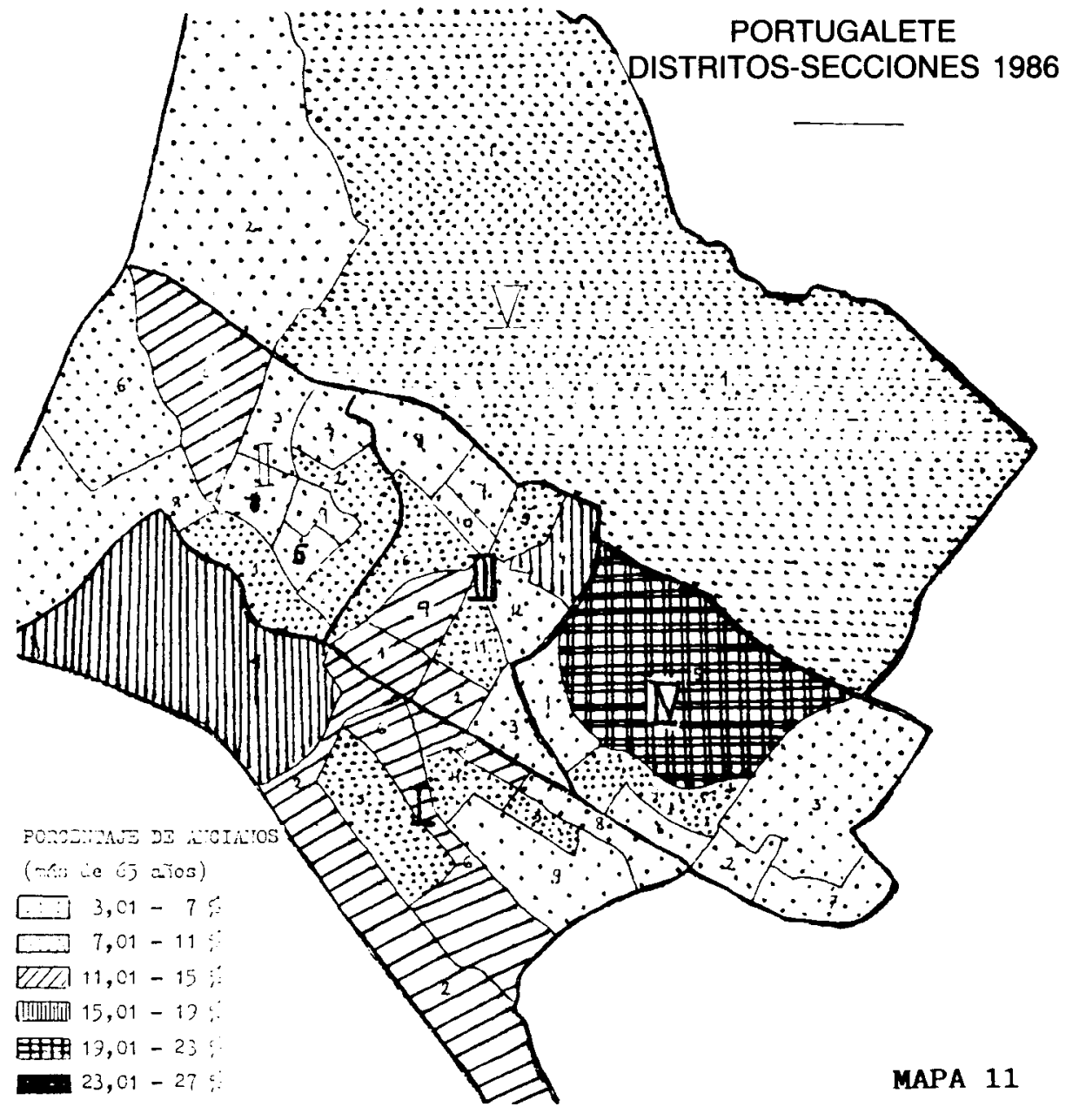




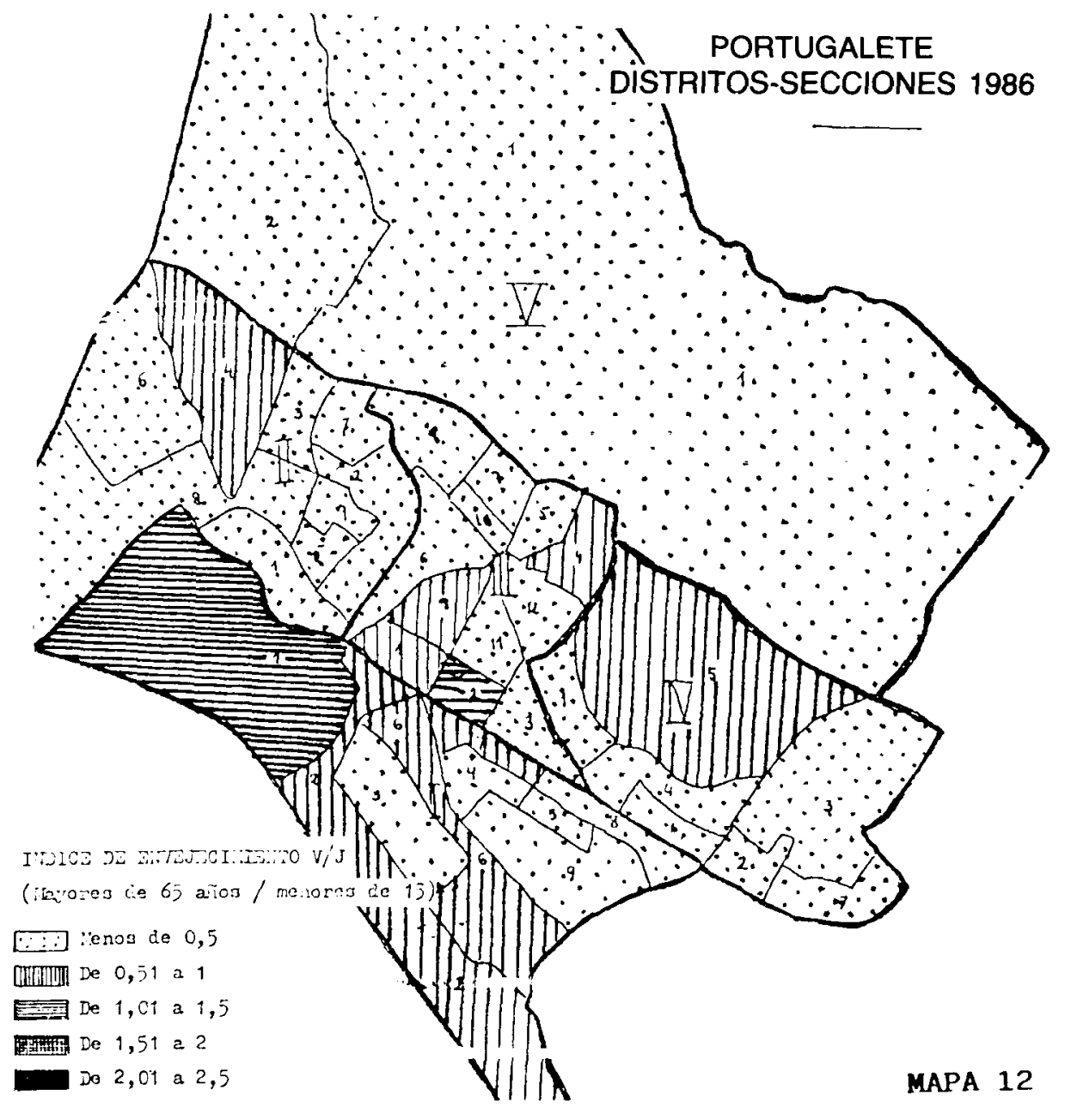




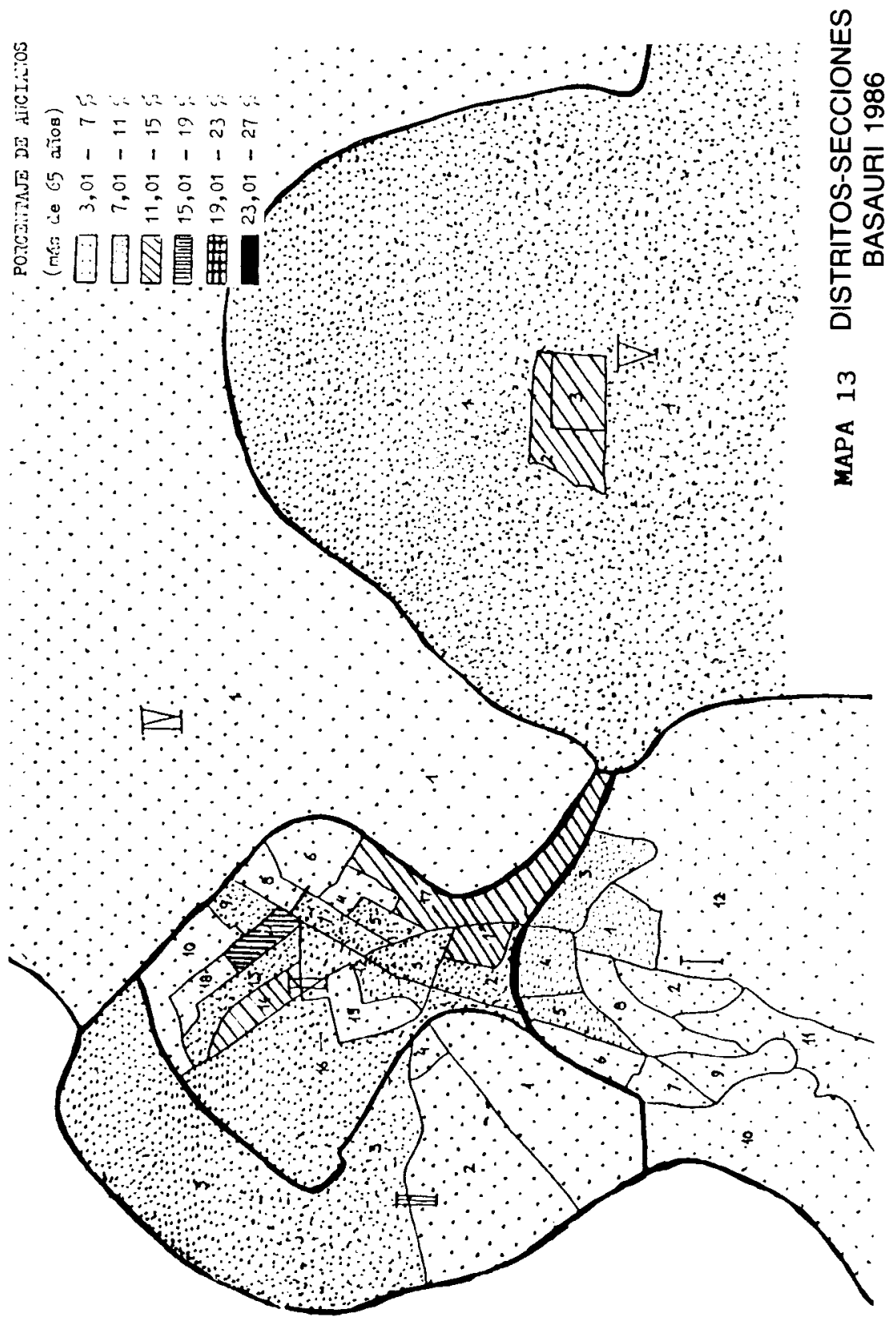




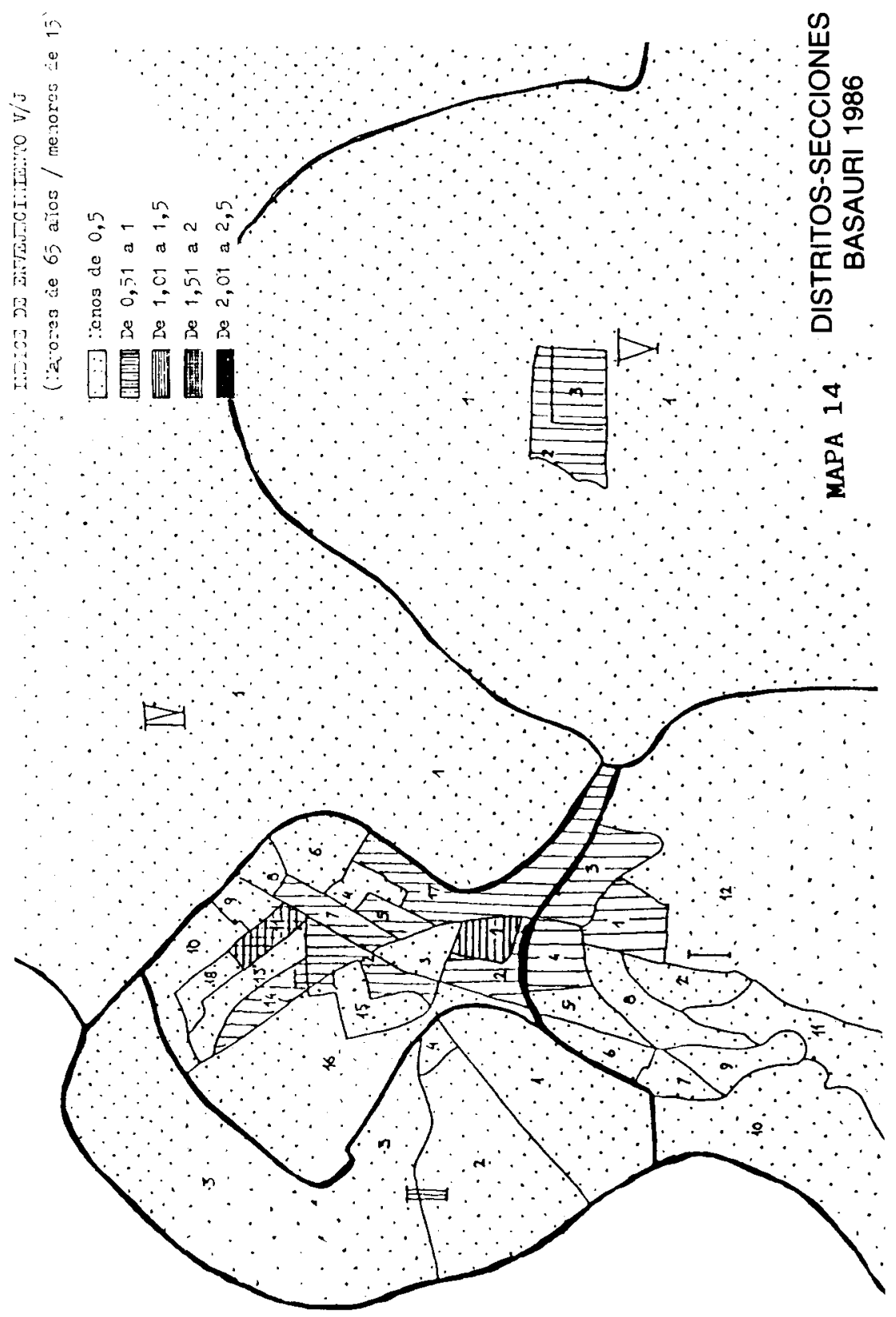




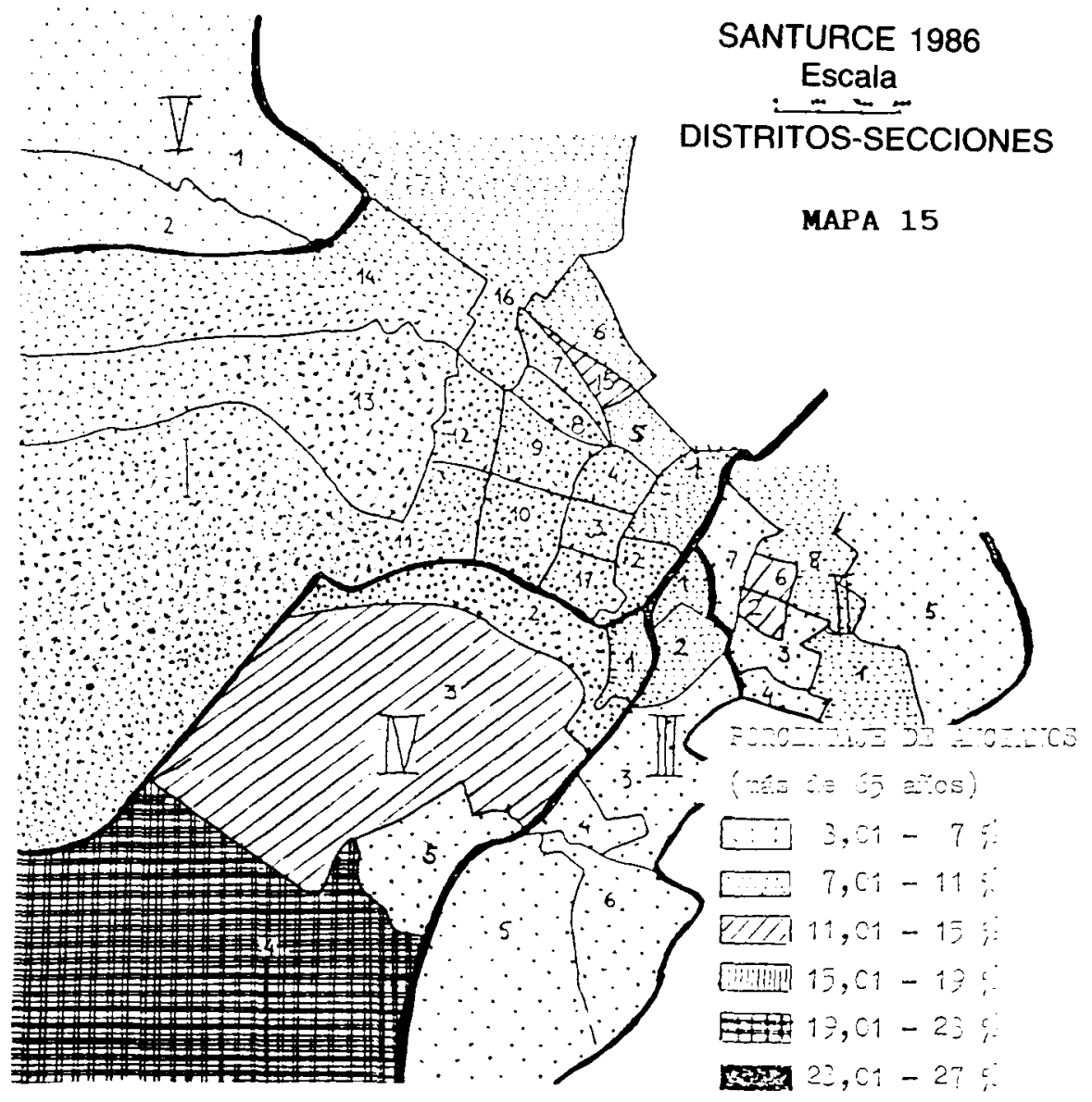




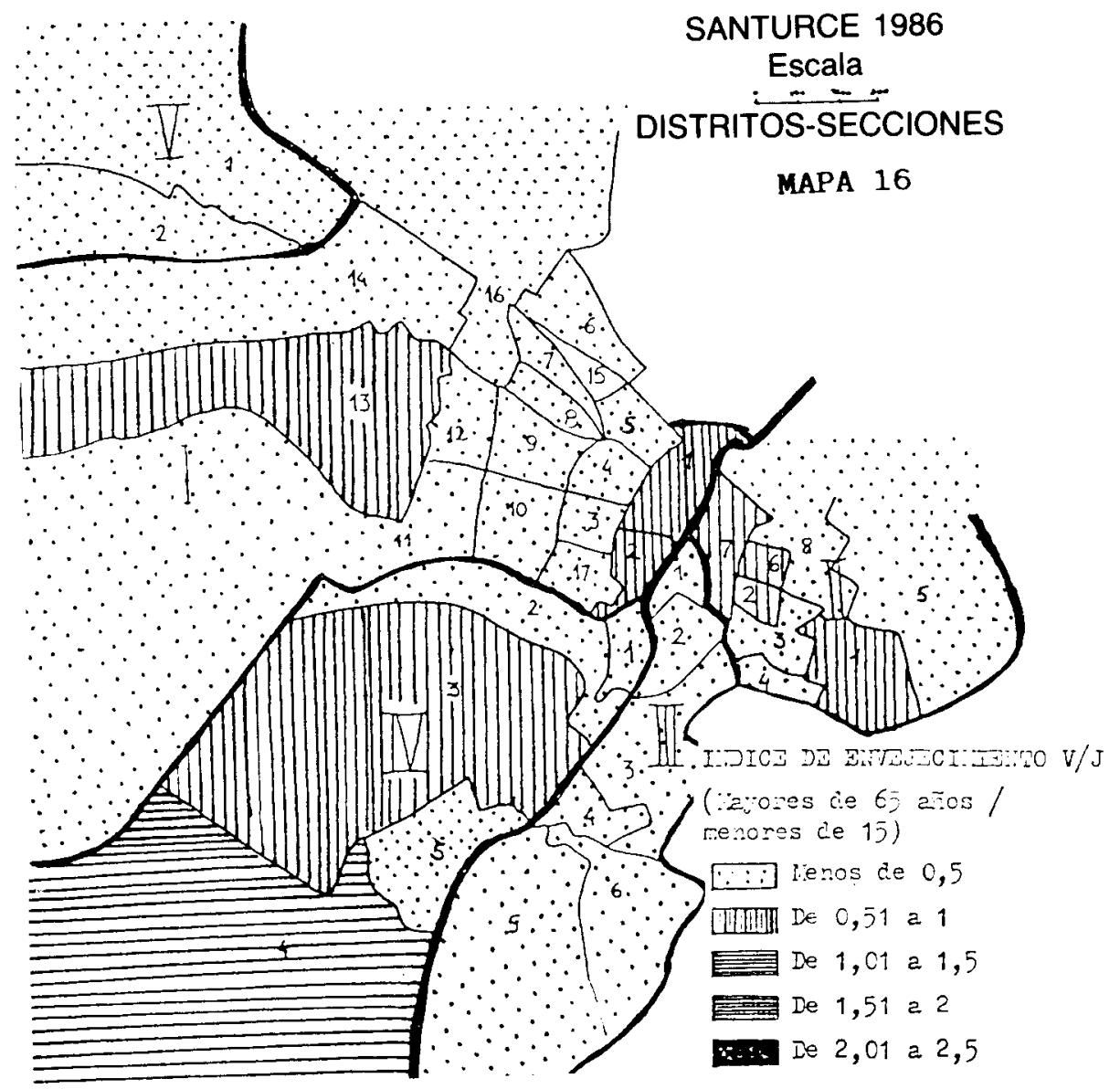




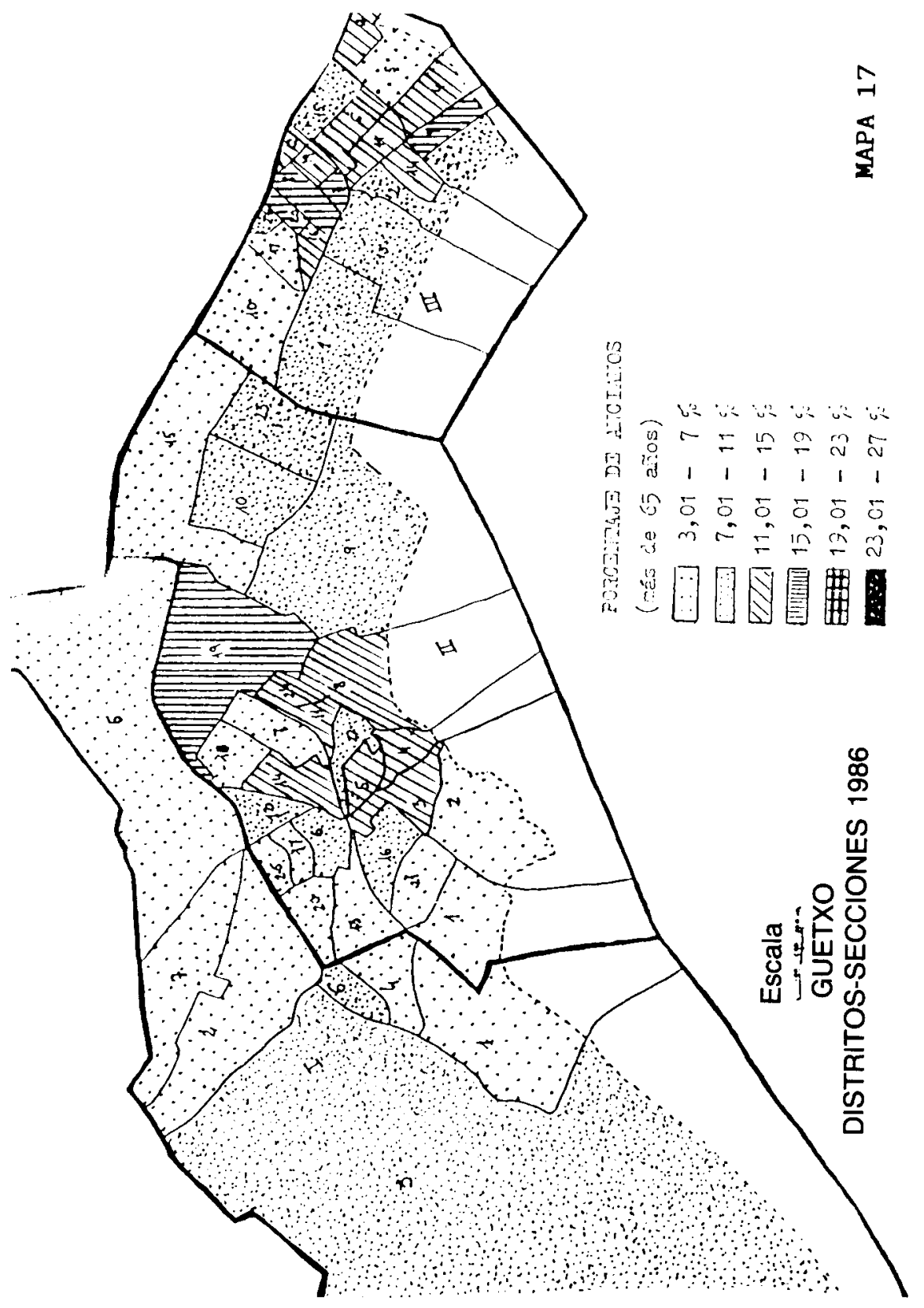




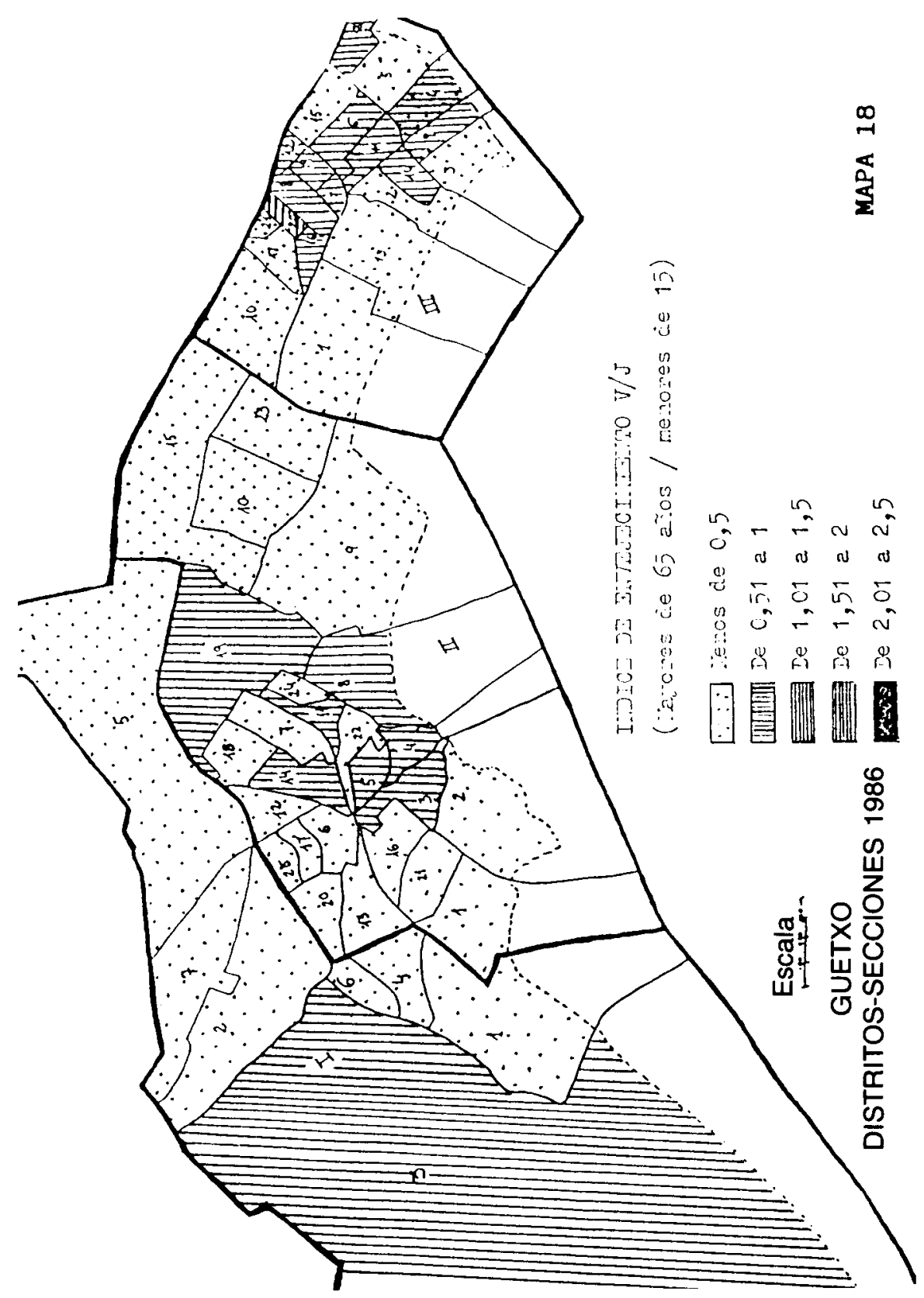




\section{BILBAO}

Recta de regresión ancianos/distancia

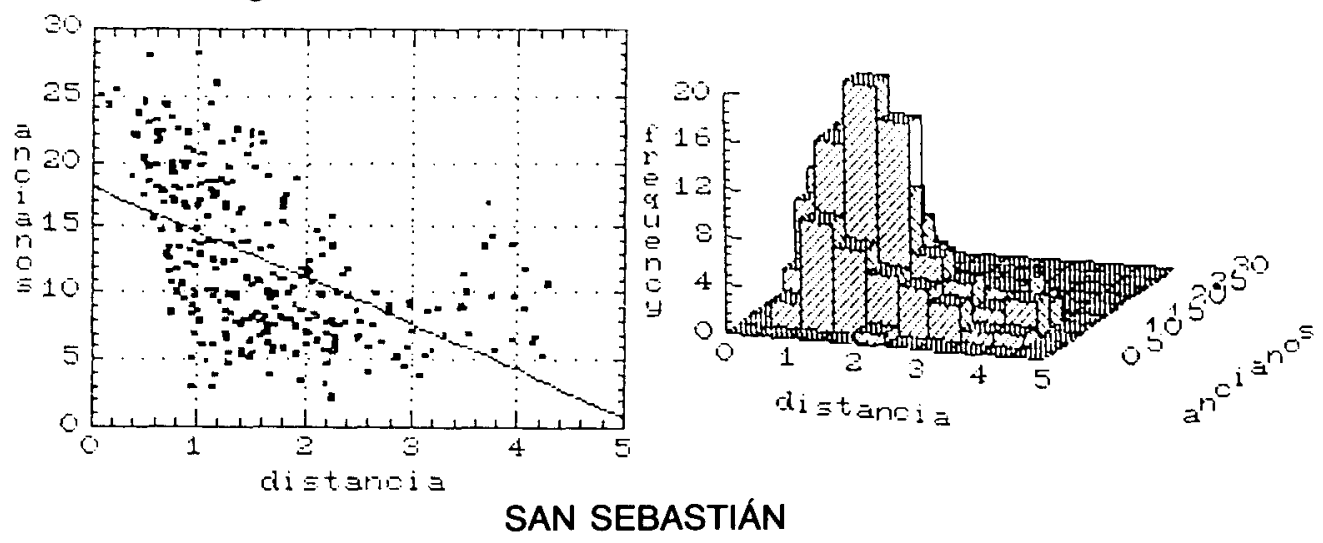

Recta de regresión ancianos/distancia
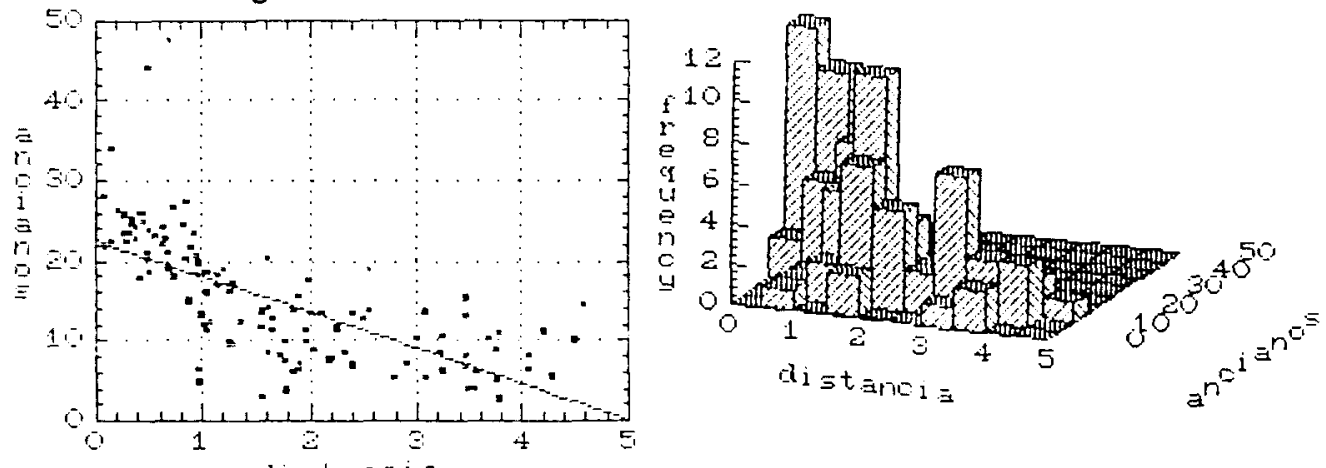

$d i \equiv t \equiv t r i$

\section{VITORIA}

Recta de regresión ancianos/distancia
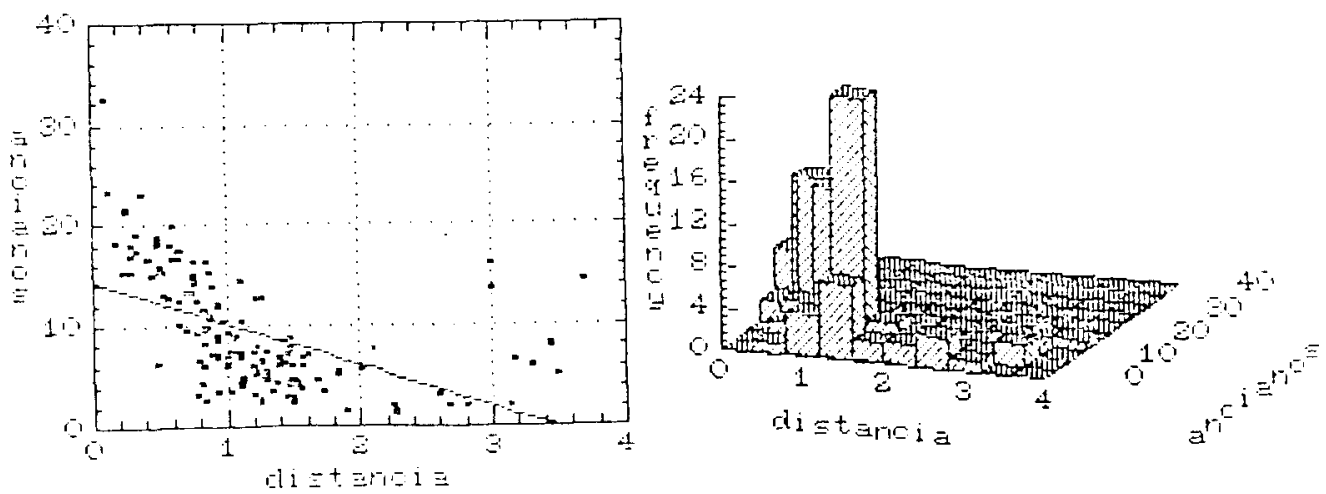
La diferenciación espacial del envejecimiento demográfico...

RECTAS DE REGRESIÓN ANCIANOS/DISTANCIA DE CIUDADES DE MAS DE $50.000 \mathrm{H}$. DEL PAIIS VASCO
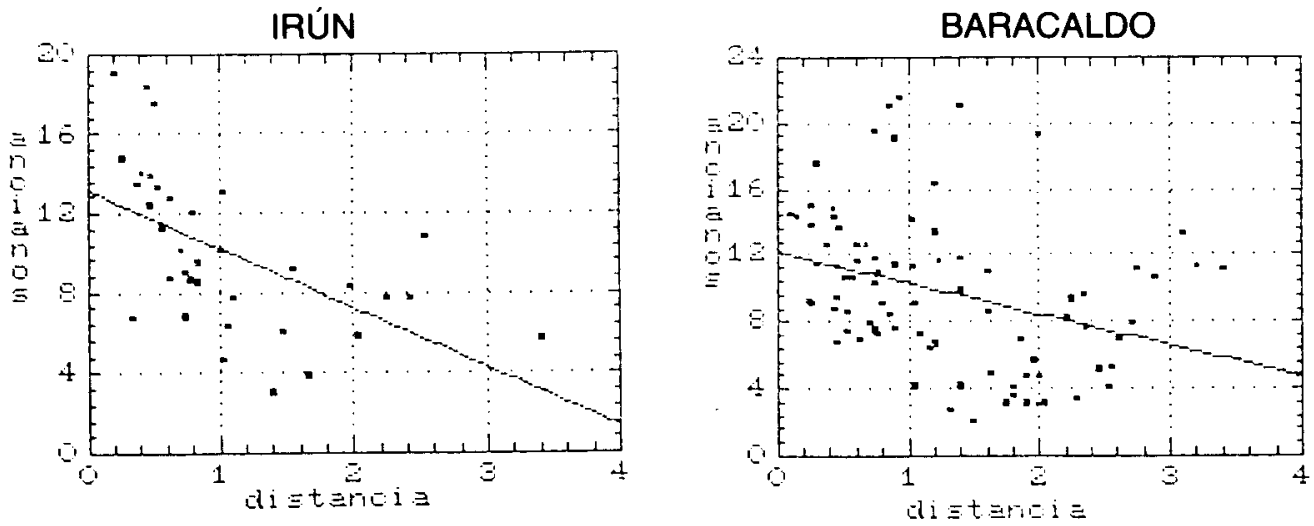

PORTUGALETE
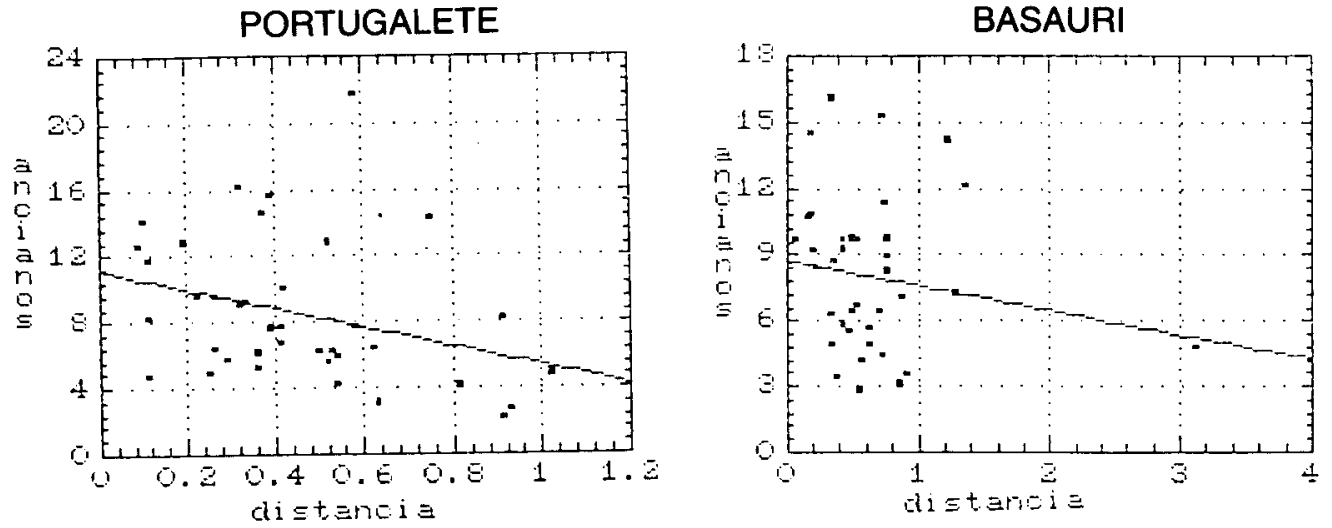

SANTURCE
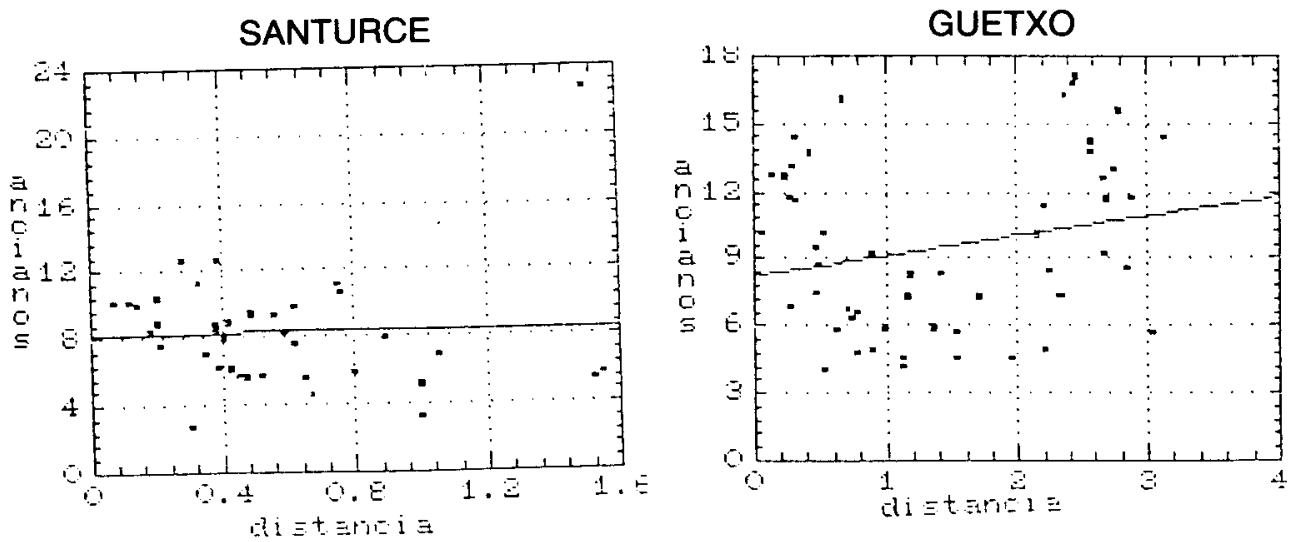


\section{BIBLIOGRAFIA}

Aguilera, M. ${ }^{a}$ J., Borderías, M. ${ }^{a}$ P., G. YANCl, M. ${ }^{a}$ P. (en prensa): “El envejecimiento demográfico de los barrios de Madrid". Homenaje al profesor Casas Torres. Zaragoza.

Aguilera, M. ${ }^{\text {a }}$ J., G. YANCI, M. ${ }^{a}$ P., 1988: "La diferenciación espacial del envejecimiento demográfico de la Comunidad Autónoma de Madrid". En Revista de la Facultad de Geografía e Historia de la UNED, n. ${ }^{\circ 3}$, p. 73-106.

-1989: "Los contrastes del envejecimiento demográfico entre el Municipio de Madrid y su Comunidad Autónoma". En Actas de /l Jornadas sobre Población Española. Universitat de les Illes Balears. Mayo 1989. p. 69-79.

Gaymus, J., Paillat, P., Parant, A., 1985: Vieillissement de la population et activités locals. París, PUF, Cahier $\mathrm{n} .^{\circ} 109,328 \mathrm{p}$.

Gonzalez Yanci, M. ${ }^{a}$ P., Aguilera Arilla, M. ${ }^{a}$ J., 1989: “La diferenciación espacial del envejecimiento demográfico en los núcleos urbanos españoles". En Actas de II Jornadas sobre Población Española. Universitat de les Illes Balears Mayo, 1989. p. 249-262.

PaIllat, P., PARANt, A., 1980: Le vieillissement de la campagne française. París, PUF, Cahier n. ${ }^{\circ} 88,294 \mathrm{p}$.

Trigo Portela, J., 1984: “Implicaciones económicas del envejecimiento de la población". En Cuadernos de Economía, n. ${ }^{\circ} 33$, p. 129-145. 